\title{
Chemical Characterization of Water-Soluble Organic Acids in Size-Segregated Particles at a Suburban Site in Saitama, Japan
}

\author{
Linfa Bao and Kazuhiko Sakamoto* \\ Department of Environmental Science and Technology, Graduate School of Science and Engineering, Saitama University, \\ 255 Shimo-Okubo, Sakura, Saitama 338-8570, Japan
}

*Corresponding author. Tel: +81-48-858-3519, E-mail: sakakazu@env.gse.saitama-u.ac.jp

\begin{abstract}
Saturated $n$-dicarboxylic acids $\left(\mathrm{C}_{2}-\mathrm{C}_{7}, \mathrm{C}_{9}\right)$, unsaturated dicarboxylic acids (maleic, fumaric, phthalic acid), ketocarboxylic acids (pyruvic, glyoxylic acid), and dicarbonyls (glyoxal, methylglyoxal) were determined in size-segregated samples with a high-volume Andersen air sampler at a suburban site in Saitama, Japan, May 12-17 and July 24-27, 2007 and January $22-31,2008$. The seasonal average concentrations of these detected organic acids were $670 \mathrm{ng} / \mathrm{m}^{3}$, accounting for about $4.4-5.7 \%(\mathrm{C} / \mathrm{C})$ of water-soluble organic carbon (WSOC) and $2.3-3.6 \%$ (C/C) of organic carbon (OC). The most abundant species of dicarboxylic acids was oxalic acid, followed by malonic, phthalic, or succinic acids. Glyoxylic acid and methyglyoxal were most abundant ketocarboxylic acid and dicarbonyl, respectively. Seasonal differences, sizesegregated concentrations, and the correlations of these acids with ambient temperatures, oxidants, elemental carbon (EC), OC, WSOC, and ionic components were also discussed in terms of their corresponding sources and possible secondary formation pathways. The results suggested that photochemical reactions contributed more to the formation of particulate organic acids in Saitama suburban areas than did direct emissions from anthropogenic and natural sources. However, direct emissions of vehicles were also important sources of several organic acids in particles, such as phthalic and adipic acids, especially in winter.
\end{abstract}

Key words: Dicarboxylic acids, Ketocarboxylic acids, Size distribution, Suburban aerosols, Secondary formation

\section{INTRODUCTION}

Water-soluble organic compounds have been identi- fied on the basis of their solubility, condensability, and atmospheric occurrence (Saxena and Hildemann, 1996). They include organic anions, dicarboxylic acids, ketocarboxylic acids, dicarbonyls, carbohydrates, amino acids, aliphatic amines, urea, and some miscellaneous multifunctional compounds containing multiple hydroxyl, carboxyl, and carbonyl groups. Lowmolecular-weight acidic compounds have been reported to account for $2-8 \%$ of water-soluble organic carbon (WSOC), though some researchers have reported this percentage to be as high as $15 \%$ (Falkovich, et al., 2005; Graham et al., 2002; Narukawa et al., 1999). In particular, water-soluble dicarboxylic acids may affect the hygroscopic and cloud-nucleating properties of aerosols (Abbatt et al., 2005; Peng et al., 2001; Cruz and Pandis, 1998).

So far, most studies on dicarboxylic acids and their salts have focused on their chemical characterization in TSP or $\mathrm{PM}_{10}$ with high-volume samplers ( $\mathrm{Li}$ and Yu, 2005; Limbeck et al., 2001; Rohrl and Lammel, 2001; Kawamura, 1993a). However, only limited size distribution data for dicarboxylic acids have been reported (Hsieh et al., 2007; Yao et al., 2002; Kerminen et al., 2000, 1999). These size distribution results were determined by means of an ion chromatograph, including only low-molecular-weight dicarboxylic acids $\left(\mathrm{C}_{2}-\mathrm{C}_{6}\right)$; there is less information on size-distributions of other dicarboxylic acids (such as phthalic acid and azelaic acid), ketocarboxylic acids and dicarbonyls. The presence of dicarboxylic acids in suspended particles may result from direct emissions (e.g., automobile exhaust, fossil fuel combustion, biomass burning) or from photochemical oxidation of organic precursors of both anthropogenic and biogenic origin (Hsieh et al., 2007; Kawamura and Yasuib, 2005; Kerminen et al., 2000; Chebbi and Carlier, 1996). The formation pathways for particulate organic acids are largely unknown but may include condensation from the gas phase, liquid-phase production in aqueous aerosol particles or in cloud or fog droplets, and heterogeneous 
reactions of precursor species at gas-particle interfaces (Kerminen et al., 1999; Kawamura et al., 1996). Therefore, a more detailed understanding of dicarboxylic acids in size-segregated particles, including their relationship with WSOC, organic carbon (OC), and elemental carbon (EC) in different environments, is still required.

In this study, normal saturated and unsaturated dicarboxylic acids, ketocarboxylic acids, and dicarbonyls were measured in size-segregated samples with a highvolume Andersen air sampler at a suburban site in Saitama, Japan. To better understand sources and formation pathways of organic acids, WSOC, OC, EC, and the main ionic components in the samples were also analyzed.

\section{EXPERIMENTAL}

\section{1 Sampling}

Atmospheric samples of suspended particulate matter (SPM) were collected at Saitama University, located in a suburban area of Saitama, about $30 \mathrm{~km}$ to the northwest of central Tokyo and about $4 \mathrm{~km}$ to the east of the business center of Saitama City, which has a population of more than one million (Jiang et al., 2006). The sampling site was located on top of a 10story office building at the University, and about $37 \mathrm{~m}$ above the ground level to avoid possible interference from local emission sources. Sampling was carried out during May 12-17, 2007 ( $n=3,47.5$ hours for each sample), July 24-27, 2007 ( $n=4,23.5$ hours for each sample) and January 22-31, $2008(n=5,47.5$ hours for each sample).

The size-segregated samples were collected on quartz fiber filters (2500QAST, Pallflex; Shibata Scientific Technology Ltd., Tokyo, Japan) using a highvolume Andersen air sampler (AH-600F, Shibata Scientific Technology Ltd.) with standard four stage cascade impactors, which separated the particles into five size fractions (equivalent aerodynamic diameters: $<1.1,1.1-2.0,2.0-3.3,3.3-7.0$, and $>7.0 \mu \mathrm{m})$. After sampling, loaded filters were stored in a refrigerator at about $-40^{\circ} \mathrm{C}$ before chemical analysis to prevent the evaporation of volatile components.

\section{2 Analysis}

Water-soluble dicarboxylic acids, ketocarboxylic acids, and dicarbonyls in filter samples were analyzed by means of $\mathrm{BF}_{3} / n$-butanol derivatization to their esters followed by gas chromatography/mass spectrometry (GC/MS) determination (Kawamura and Yasuib, 2005; Kawamura, 1993a). One-quarter of each filter was ultrasonically extracted with $15 \mathrm{~mL}$ of ultra- pure water in an ice bath for $20 \mathrm{~min}$, and this process was repeated more second times. The extracts were passed through a hydrophilic polytetrafluoroethylene filter (Advantec DISMIC-13HP) to remove filter debris and concentrated to $c a .0 .5 \mathrm{~mL}$ in a rotary evaporator under vacuum at $48^{\circ} \mathrm{C}$. After the extracts were further dried under a nitrogen stream, $14 \% \mathrm{BF}_{3} / n$ butanol $(300 \mu \mathrm{L})$ was added to derivatize the carboxyl groups to butyl esters and the aldehyde groups to dibutoxy acetals at $100^{\circ} \mathrm{C}$ for $30 \mathrm{~min}$. After adding 300 $\mu \mathrm{L}$ of acetonitrile and $10 \mathrm{~mL}$ of pure water, the derivatives were extracted with $10 \mathrm{~mL}$ of $n$-hexane, and then were washed with pure water $(10 \mathrm{~mL})$ two times. The $n$-hexane phase was concentrated under a nitrogen stream to $c a .50 \mu \mathrm{L}$. After adding the internal standard compound (tridecane), the derivatives were dissolved in $100 \mu \mathrm{L}$ of $n$-hexane for GC/MS analysis.

Dibutyl esters and other derivatives were determined using a GC/MS (GCMS-QP 5050, Shimadzu Corporation, Kyoto, Japan) equipped with a split/splitless injector and a fused silica capillary column (DB-5; 30.0 $\mathrm{m} \times$ I.D. $0.32 \mathrm{~mm} \times 0.25 \mu \mathrm{m}$ film thickness). The operating conditions were: inject temperature of $300^{\circ} \mathrm{C}$; column initial temperature of $50^{\circ} \mathrm{C}$ for 2 minutes, ramped to $120^{\circ} \mathrm{C}$ at $30^{\circ} \mathrm{C} \mathrm{min}^{-1}$ and then to $250^{\circ} \mathrm{C}$ at $8^{\circ} \mathrm{C} \min ^{-1}$ with a 5 min hold; helium carrier gas (flow rate, $50 \mathrm{~mL} / \mathrm{min}$; pressure, $80 \mathrm{kPa}$ ). The compounds were identified by comparison of GC retention times with mass chromatograms of authentic standards. Each chromatograph was calibrated with standard solutions prepared with target compound reagents to contain quantities to $100,250,500,1,000,2,500,5,000$, and $10,000 \mathrm{ng}$ of each compound. Retention times, slopes, and $R$-squared values for calibration curves of target compounds, including saturated $n$-dicarboxylic acids $\left(\mathrm{C}_{2}\right.$ : oxalic, $\mathrm{C}_{3}$ : malonic, $\mathrm{C}_{4}$ : succinic, $\mathrm{C}_{5}$ : glutaric, $\mathrm{C}_{6}$ : adipic, $\mathrm{C}_{7}$ : pimelic, and $\mathrm{C}_{9}$ : azelaic acid), unsaturated dicarboxylic acids (M: maleic, F: fumaric, and $\mathrm{Ph}$ : phthalic acid), ketocarboxylic acids (Pyr: pyruvic and $\mathrm{WC}_{2}$ : glyoxilic acid), and dicarbonyls (Gly: glyoxal and MeGly: methylglyoxal), are shown in Table 1.

$\mathrm{OC}$ and $\mathrm{EC}$ in filter samples were analyzed by means of a thermal/optical carbon analyzer (TOCA, DRI model 2001, Shibata Scientific Technology Ltd.), following The IMPROVE thermal/optical reflectance protocol (Chow and Watson, 2002). In the protocol, a $0.503-\mathrm{cm}^{2}$ punch aliquot of a sample quartz filter was heated at temperatures of $120^{\circ} \mathrm{C}\left(\mathrm{OC}_{1}\right), 250^{\circ} \mathrm{C}\left(\mathrm{OC}_{2}\right)$, $450^{\circ} \mathrm{C}\left(\mathrm{OC}_{3}\right)$, and $550^{\circ} \mathrm{C}\left(\mathrm{OC}_{4}\right)$ in a non-oxidizing helium atmosphere, and at $550^{\circ} \mathrm{C}\left(\mathrm{EC}_{1}\right), 700^{\circ} \mathrm{C}\left(\mathrm{EC}_{2}\right)$, and $800^{\circ} \mathrm{C}\left(\mathrm{EC}_{3}\right)$ in an oxidizing atmosphere of $2 \%$ oxygen and $98 \%$ helium. The repeatability, determined from replicate analyses, was better than $5 \%$ for total carbon (TC) and 10\% for OC and EC (Jiang et al., 
Table 1. Retention times, slopes and $R$-squared values (regression coefficients) for calibration curves of target compounds.

\begin{tabular}{|c|c|c|c|c|}
\hline$\overline{\text { Retention time }}$ & Target compound & Type & Slope & $\overline{\mathrm{R}^{2} \text { value }}$ \\
\hline 5.91 & Methylglyoxal (MeGly) & Dicarbonyl & 1.42 & 0.977 \\
\hline 6.72 & Oxalic $\left(\mathrm{C}_{2}\right)$ & Saturated dicarboxylic acid & 2.25 & 0.994 \\
\hline 7.57 & Malonic $\left(\mathrm{C}_{3}\right)$ & Saturated dicarboxylic acid & 1.77 & 0.998 \\
\hline 8.76 & Maleic (M) & Unsaturated dicarboxylic acid & 1.95 & 0.998 \\
\hline 9.04 & Succinic $\left(\mathrm{C}_{4}\right)$ & Saturated dicarboxylic acid & 1.90 & 0.998 \\
\hline 9.33 & Fumaric $(\mathrm{F})$ & Unsaturated dicarboxylic acid & 1.75 & 0.997 \\
\hline 9.47 & Pyruvic (Pyr) & Ketocarboxylic acids & 1.60 & 0.974 \\
\hline 9.66 & Glyoxylic $\left(\mathrm{WC}_{2}\right)$ & Ketocarboxylic acids & 3.24 & 0.971 \\
\hline 10.32 & Glutaric $\left(\mathrm{C}_{5}\right)$ & Saturated dicarboxylic acid & 1.77 & 0.998 \\
\hline 11.69 & Adipic acid $\left(\mathrm{C}_{6}\right)$ & Saturated dicarboxylic acid & 1.56 & 0.988 \\
\hline 11.95 & Glyoxal (Gly) & Dicarbonyl & 4.26 & 0.991 \\
\hline 12.95 & Pimelic $\left(\mathrm{C}_{7}\right)$ & Saturated dicarboxylic acid & 1.08 & 0.994 \\
\hline 14.19 & Phthalic acid $(\mathrm{Ph})$ & Unsaturated dicarboxylic acid & 1.69 & 0.991 \\
\hline 15.47 & Azelaic $\left(\mathrm{C}_{9}\right)$ & Saturated dicarboxylic acid & 0.95 & 0.992 \\
\hline
\end{tabular}

2006).

One-eighth of each filter was also extracted with 10 $\mathrm{mL}$ of ultrapure water in an ice bath for $20 \mathrm{~min}$. The extract was used to analyze WSOC with a total organic carbon analyzer (TOC-VCHP, Shimadzu Corporation) and ionic components (anions: $\mathrm{NO}_{3}{ }^{-}, \mathrm{SO}_{4}{ }^{2-}$, and $\mathrm{Cl}^{-}$; cations: $\mathrm{K}^{+}, \mathrm{Na}^{+}, \mathrm{NH}_{4}^{+}$, and $\mathrm{Ca}^{2+}$ ) with an ion chromatography system (DX-100, DIOTEC Company of Tokyo, Tokyo, Japan). In addition, atmospheric pollutant and meteorological information (such as ambient temperature, relative humidity, and oxidants) was provided by the Atmospheric Environmental Regional Observation System of Japan, at a site located in the Saitama Institute of Public Health, which is about 500 $\mathrm{m}$ from the roadside site.

\section{RESULTS AND DISCUSSION}

\subsection{Molecular Compositions of Water-soluble Organic Acids in Suspended Particulate Matter}

All target compounds in the size-segregated SPM samples were detected, with obvious peaks being observed in the chromatograms. Table 2 shows the total average concentrations of dicarboxylic acids, ketocarboxylic acids, and dicarbonyls detected in the suburban samples during May 12-17 (spring) and July 24-27 (summer), 2007, and January 22-31 (winter), 2008. The results indicate that the most abundant species in the SPM for all suburban samples was oxalic acid $\left(\mathrm{C}_{2}\right)$, followed by malonic $\left(\mathrm{C}_{3}\right)$, phthalic $(\mathrm{Ph})$ or succinic acid $\left(\mathrm{C}_{4}\right)$. Longer chain $n$-dicarboxylic acids were less abundant, except for azelaic acid $\left(\mathbf{C}_{9}\right)$, which was more abundant than glutaric $\left(\mathrm{C}_{5}\right)$, adipic $\left(\mathrm{C}_{6}\right)$, and pimelic acid $\left(\mathrm{C}_{7}\right)$.

Glyoxylic acid $\left(\mathrm{WC}_{2}\right)$ was an abundant species in all target compounds, and its predominance in ketocarboxylic acids detected in urban atmospheres has been reported (Ho et al., 2006; Kawamura and Yasuib, 2005). Glyoxal (Gly) and methylglyoxal (MeGly) were detected at abundant concentrations in SPM, and MeGly was the most abundant dicarbonyl observed in the particles, most likely because Gly is largely present in the gas phase (Oritz et al., 2006).

Most dicarboxylic acids were more abundant in summer than in other seasons, with the sum of these acids' concentrations increasing by 3.6 times in the summer relative to the other seasons (Table 2). Since mixing heights in summer are high, accumulation was not likely the reason for the higher observed concentrations of these acids during this season. Instead, their secondary formations are expected to be important in summer. In addition, a higher abundance of $\mathrm{Ph}$ in winter samples suggests that aromatic hydrocarbons are important precursors of $\mathrm{Ph}$ in Saitama.

\section{2 Concentration Variations of Water-soluble Organic Acids in Size-segregated Particles}

Size distribution data are useful for understanding the formation pathways of atmospheric species. As shown in Fig. 1, sulfate was present mostly in fine particles $(<1.1 \mu \mathrm{m})$. Previous studies of sulfate size distribution (Yao et al., 2002; Blando and Turpin, 2000; Kerminen et al., 1999) have reported a bimodal distribution of sulfate with mass mean diameters of about $0.2 \pm 0.1 \mu \mathrm{m}$ and $0.7 \pm 0.3 \mu \mathrm{m}$. The smaller mode is generally ascribed to gas condensation, whereas the larger mode is ascribed to fog or cloud formation (Kerminen et al., 1999). However, the size distribution of nitrate peaked in coarse particles $(>7 \mu \mathrm{m}$ or 3.3-7 $\mu \mathrm{m}$ ) during warm seasons (May and July), which is commonly ascribed to heterogeneous reactions, in- 
Table 2. Concentrations of individual organic acids, OC, EC, WSOC, and ionic components in SPM.

\begin{tabular}{|c|c|c|c|c|c|c|}
\hline \multirow{2}{*}{ Target compound } & \multicolumn{2}{|c|}{ Spring } & \multicolumn{2}{|c|}{ Summer } & \multicolumn{2}{|c|}{ Winter } \\
\hline & Mean & S.D. & Mean & S.D. & Mean & S.D. \\
\hline Water-soluble organic acids & \multicolumn{6}{|c|}{ Concentrations $\left(\mathrm{ng} / \mathrm{m}^{3}\right)$} \\
\hline Oxalic $\left(\mathrm{C}_{2}\right)$ & 243 & 45 & 472 & 187 & 94 & 24 \\
\hline Malonic $\left(\mathrm{C}_{3}\right)$ & 59 & 20 & 166 & 49 & 15 & 5 \\
\hline Succinic $\left(C_{4}\right)$ & 42 & 14 & 103 & 27 & 23 & 8 \\
\hline Glutaric $\left(\mathrm{C}_{5}\right)$ & 11.7 & 3.8 & 37.4 & 5.1 & 7.0 & 2.6 \\
\hline $\operatorname{Adipic}\left(\mathrm{C}_{6}\right)$ & 7.3 & 2.5 & 18.0 & 6.9 & 7.9 & 2.7 \\
\hline Pimelic $\left(\mathrm{C}_{7}\right)$ & 3.3 & 2.5 & 4.7 & 2.4 & 2.8 & 2.1 \\
\hline Azelaic $\left(\mathrm{C}_{9}\right)$ & 16.3 & 9.5 & 35.6 & 12.3 & 23.9 & 16.1 \\
\hline Maleic (M) & 4.2 & 2.1 & 10.4 & 3.3 & 6.2 & 2.4 \\
\hline Fumaric (F) & 2.1 & 0.2 & 6.5 & 3.7 & 5.5 & 3.0 \\
\hline Phthalic (Ph) & 38 & 1 & 149 & 64 & 505 & 15 \\
\hline Glyoxylic $\left(\mathrm{WC}_{2}\right)$ & 33.1 & 14.1 & 73.8 & 32.0 & 21.7 & 9.0 \\
\hline Pyruvic (Pyr) & 23.0 & 7.9 & 55.0 & 19.0 & 18.4 & 5.2 \\
\hline Glyoxal (Gly) & 5.9 & 1.8 & 14.1 & 5.0 & 6.3 & 2.2 \\
\hline Methylglyoxal (MeGly) & 19.2 & 2.2 & 51.8 & 30.9 & 14.9 & 4.4 \\
\hline Total organic acids $(\mathrm{OA})$ & 508 & 121 & 1198 & 366 & 303 & 88 \\
\hline OC/EC/WSOC/ionic components & \multicolumn{6}{|c|}{ Concentrations $\left(\mu \mathrm{g} / \mathrm{m}^{3}\right)$} \\
\hline Organic carbon $(\mathrm{OC})$ & 5.90 & 1.99 & 12.06 & 5.17 & 5.18 & 1.96 \\
\hline Pyrolytic OC (Py-OC) & 1.93 & 0.37 & 3.53 & 1.62 & 1.08 & 0.48 \\
\hline Elemental carbon (EC) & 0.90 & 0.10 & 1.44 & 0.36 & 1.24 & 0.55 \\
\hline Total carbon (TC) & 6.79 & 1.94 & 13.50 & 5.53 & 6.42 & 2.47 \\
\hline Water-soluble OC (WSOC) & 3.33 & 0.59 & 7.64 & 2.91 & 2.74 & 1.23 \\
\hline Chloride $\left(\mathrm{Cl}^{-}\right)$ & 0.58 & 0.11 & 1.15 & 0.51 & 1.32 & 0.70 \\
\hline Nitrate $\left(\mathrm{NO}_{3}^{-}\right)$ & 3.09 & 0.56 & 7.19 & 3.13 & 2.15 & 1.23 \\
\hline Sulfate $\left(\mathrm{SO}_{4}^{2-}\right)$ & 5.09 & 0.81 & 12.00 & 4.52 & 2.15 & 0.82 \\
\hline Sodium $\left(\mathrm{Na}^{+}\right)$ & 0.68 & 0.12 & 0.32 & 0.12 & 0.24 & 0.15 \\
\hline Ammonium $\left(\mathrm{NH}_{4}{ }^{+}\right)$ & 2.29 & 0.35 & 4.95 & 2.20 & 1.37 & 0.55 \\
\hline Calcium $\left(\mathrm{Ca}^{2+}\right)$ & 0.51 & 0.27 & 1.46 & 0.66 & 0.36 & 0.13 \\
\hline
\end{tabular}

cloud processes involving reactions with sea-salt aerosols, or both (Yao et al., 2002). During warm seasons, nitrate in fine particles tends to transform into gaseous compounds due to the volatility of ammonium nitrate, which caused relatively lower concentration of nitrate in fine particles. During the cold period (January), nitrate in Saitama suburban samples had a similar size distribution as sulfate, and mainly existed in fine particles.

The size-segregated concentrations of TOC, WSOC and selected organic acids in suburban particles are also shown in Fig. 1. In spring and summer, WSOC and most organic acids had size distributions similar to those observed for sulfate, indicating that similar formation pathways had occurred. Using the size distribution of sulfate as a reference, most organic acids in fine particles $(<1.1 \mu \mathrm{m})$ are expected to be obvious distributions with Aitken mode and accumulation mode. In winter, water-soluble organic acids, especially adipic and phthalic acids, were more prevalent in $>1.1-\mu \mathrm{m}$ particles than they were during warm periods. The following differences between summer and winter seasons can explain this observed difference in partitioning into $>1.1-\mu \mathrm{m}$ particles: i) the lower tem- perature during winter nights compared with summer nights; ii) changes in gas/particle repartitioning for semi-volatile species between warm and cold conditions (Jaffrezo et al., 2005); and iii) different oxidation and formation pathways.

\section{3 Correlations between Selected Organic Acids and Temperature, Oxidants, Sulfate, and Nitrate}

The presence of water-soluble organic acids in SPM may result from direct emissions and secondary photochemical reactions. Strong correlations were observed among $\mathrm{C}_{2}, \mathrm{C}_{3}, \mathrm{C}_{4}$, and $\mathrm{WC}_{2}(r>0.92$ in Table $3, n=12$, $p<0.001)$, and this was consistent with atmospheric oxidation processes, which largely control the concentrations of these species in particles. Good correlation was also observed between $\mathrm{Ph}$ and $\mathrm{C}_{6}(r=0.91$ in Table 3, $n=12, p<0.001)$; these two dicarboxylic acids were well correlated with EC $(r>0.53$ in Table $3, n=12, p<0.07)$, suggesting that the source of $\mathrm{Ph}$ and $\mathrm{C}_{6}$ was related to incomplete combustion to a certain extent. $\mathrm{Ph}$, an important aromatic acid, can be directly emitted from combustion sources and also can be generated by atmospheric degradation of aro- 

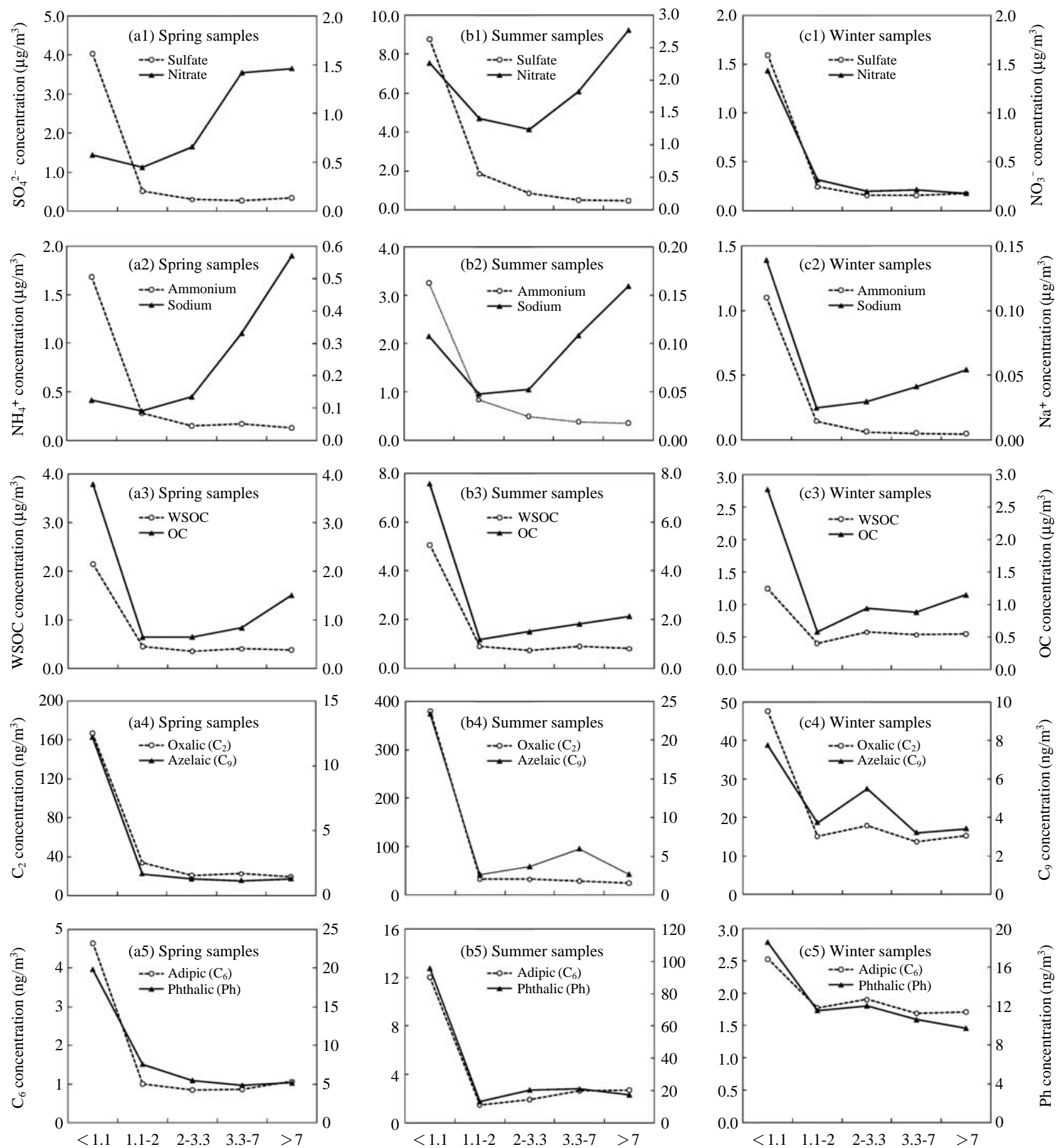

Fig. 1. Size-segregated concentrations of sulfate, nitrate, ammonium, sodium, WSOC, OC, and selected organic acids in suburban particles in spring (a), summer (b), and winter (c).

matic hydrocarbons such as naphthalene (Ho et al., 2006; Kawamura and Ikushima, 1993b). Laboratory experiments have shown that $\mathrm{C}_{6}$ is produced by photochemical oxidation of cyclic alkenes, which are present in the atmosphere as a result of atmospheric emissions from internal combustion engines (Hatakeyama et al., 1987).

The different relationships between individual organic acids and ambient parameters and other pollutants may be associated with different sources and 
Table 3. Correlation coefficients among selected organic acids, OA, $\mathrm{OC}_{2}, \mathrm{Py}-\mathrm{OC}, \mathrm{EC}, \mathrm{WSOC}, \mathrm{SO}_{4}{ }^{2-}$, and oxidants in $\mathrm{SPM}$ $(n=12)$.

\begin{tabular}{|c|c|c|c|c|c|c|c|c|c|c|c|c|c|}
\hline & $\mathrm{C}_{2}$ & $\mathrm{C}_{3}$ & $\mathrm{C}_{4}$ & $\overline{C_{6}}$ & $\mathrm{Ph}$ & $\mathrm{WC}_{2}$ & $\mathrm{OA}$ & $\mathrm{OC}_{2}$ & Py-OC & $\mathrm{EC}$ & WSOC & $\mathrm{SO}_{4}^{2-}$ & Oxidants \\
\hline $\mathrm{C}_{2}$ & 1.00 & & & & & & & & & & & & \\
\hline $\mathrm{C}_{3}$ & 0.95 & 1.00 & & & & & & & & & & & \\
\hline $\mathrm{C}_{4}$ & 0.95 & 0.96 & 1.00 & & & & & & & & & & \\
\hline $\mathrm{C}_{6}$ & 0.83 & 0.75 & 0.87 & 1.00 & & & & & & & & & \\
\hline $\mathrm{Ph}$ & 0.74 & 0.69 & 0.75 & 0.91 & 1.00 & & & & & & & & \\
\hline $\mathrm{WC}_{2}$ & 0.92 & 0.93 & 0.95 & 0.85 & 0.64 & 1.00 & & & & & & & \\
\hline $\mathrm{OA}$ & 0.98 & 0.95 & 0.98 & 0.90 & 0.83 & 0.93 & 1.00 & & & & & & \\
\hline $\mathrm{OC}_{2}$ & 0.87 & 0.76 & 0.89 & 0.97 & 0.82 & 0.89 & 0.91 & 1.00 & & & & & \\
\hline Py-OC & 0.89 & 0.85 & 0.93 & 0.82 & 0.58 & 0.98 & 0.90 & 0.90 & 1.00 & & & & \\
\hline TEC & 0.38 & 0.29 & 0.44 & 0.65 & 0.53 & 0.47 & 0.46 & 0.67 & 0.50 & 1.00 & & & \\
\hline WSOC & 0.86 & 0.81 & 0.94 & 0.92 & 0.73 & 0.94 & 0.91 & 0.95 & 0.96 & 0.64 & 1.00 & & \\
\hline $\mathrm{SO}_{4}^{2-}$ & 0.97 & 0.94 & 0.96 & 0.81 & 0.70 & 0.96 & 0.96 & 0.86 & 0.94 & 0.40 & 0.91 & 1.00 & \\
\hline Oxidants & 0.90 & 0.90 & 0.88 & 0.65 & 0.55 & 0.87 & 0.87 & 0.71 & 0.84 & 0.08 & 0.76 & 0.92 & 1.00 \\
\hline
\end{tabular}

different production mechanisms. Good correlation was observed between OA and oxidants $(r=0.87$ in Table 3, $n=12, p<0.001$ ), especially in warm period (spring and summer) $(r=0.92, n=7, p<0.005)$. The increase of the correlation was found to depend on carbon chain length and on the structure of the acid species, which is consistent with results reported in previous studies (Ho et al., 2006; Kawamura and Yasuib., 2005). In particular, $C_{2}$ had the strongest correlation with oxidants $(r=0.90, n=12, p<0.001$; Fig. 2a), followed by $\mathrm{C}_{3}(r=0.90, n=12, p<0.001)$ and $\mathrm{C}_{4}$ $(r=0.88, n=12, p<0.005)$. These correlations were related to secondary photochemical processes. However, $\mathrm{Ph}$ displayed a lower correlation with oxidants ( $r=0.55, n=12, p<0.06)$ than did the other organic acids, further suggesting that its origin was primary emissions from vehicles. In addition, similar relationship was observed between all of the studied acids and daily average temperature (Fig. 2b).

Furthermore, individual organic acids were more strongly correlated with sulfate than with nitrate in SPM. $C_{2}$ is the single most abundant organic acid identified in ambient aerosols. Yu et al. (2005) observed a strong correlation between $\mathrm{C}_{2}$ and sulfate at different locations, and they argued that there exists a common dominant formation pathway of the two chemically distinct species. As shown in Fig. 3, $\mathrm{C}_{2}$ correlated very strongly with sulfate $(r=0.97, n=12, p<0.001)$ in Saitama aerosol. Sulfate is a major aerosol component whose formation pathways have been well investigated in the past few decades, and in-cloud processing is recognized as the major production pathway of sulfate (Yu et al., 2005; Yao et al., 2002). The present results also highlight the potential importance of in-cloud processing as a pathway leading to the formation of lowmolecular-weight dicarboxylic acids.
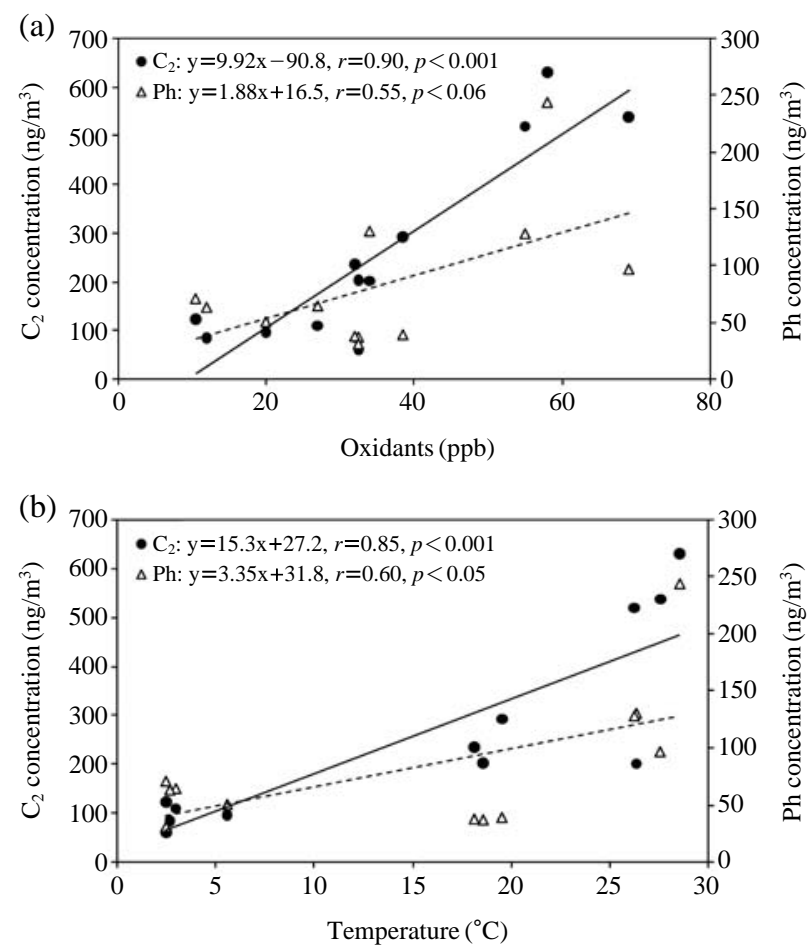

Fig. 2. Correlations of $\mathrm{C}_{2}$ and $\mathrm{Ph}$ concentrations in SPM with ambient oxidants (a) and temperature (b) in Saitama $(n=12)$.

\subsection{Relationship of Individual Organic Acids with OA, OC, EC, Py-OC, and WSOC}

To further clarify the behaviour of carbonaceous compounds, Table 4 shows concentration ratios of OA (the total of all detected organic acids, $\mu \mathrm{g}-\mathrm{C} / \mathrm{m}^{3}$ ), OC, and WSOC. Generally, the relative carbon abundances of OA in WSOC and in OC were $5.1 \%$ and $3.0 \%$, respectively. Abundances of $\mathrm{C}_{2}$ in OA, WSOC, and OC during the warm periods were higher than those during the cold periods, but $\mathrm{Ph}$ had relatively high abun- 


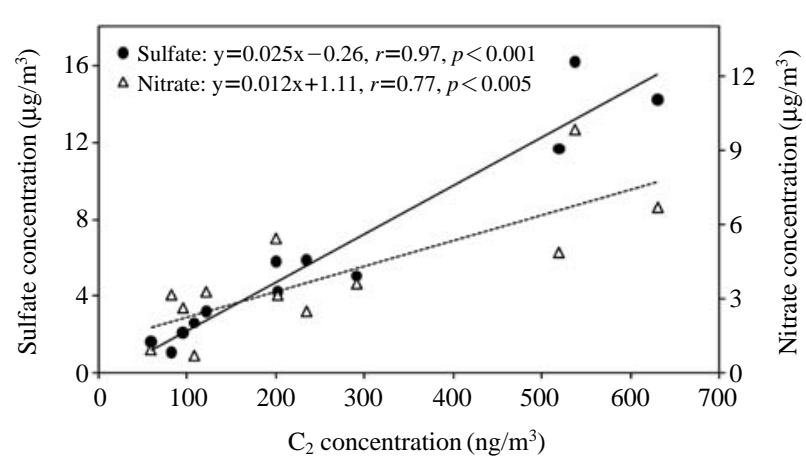

Fig. 3. Correlations of $C_{2}$ concentrations with sulfate and nitrate in SPM in Saitama $(n=12)$.

Table 4. Concentration ratios of $\mathrm{OA}\left(\mu \mathrm{g}-\mathrm{C} / \mathrm{m}^{3}\right), \mathrm{OC}, \mathrm{Py}-\mathrm{OC}$, WSOC, and EC in SPM.

\begin{tabular}{lllll}
\hline \multicolumn{1}{c}{ Ratio } & Spring & Summer & Winter & Average \\
\hline OA/WSOC & 0.053 & 0.057 & 0.044 & 0.051 \\
OA/OC & 0.030 & 0.036 & 0.023 & 0.030 \\
Py-OC/WSOC & 0.58 & 0.46 & 0.39 & 0.48 \\
Py-OC/OC & 0.33 & 0.29 & 0.21 & 0.28 \\
WSOC/OC & 0.56 & 0.63 & 0.53 & 0.58 \\
OC/EC & 6.57 & 8.39 & 4.17 & 6.38 \\
\hline
\end{tabular}

dances in winter.

$\mathrm{OC}$ and EC concentrations in the filter samples were analyzed with the TOCA using a temperature program based on the IMPROVE method. The individual organic acids in SPM had good correlations with $\mathrm{OC}_{2}(r>$ 0.76 in Table $3, n=12, p<0.005$ ), but weak correlations with $\mathrm{OC}_{1}\left(50-120^{\circ} \mathrm{C}\right)$ and $\mathrm{OC}_{4}\left(450-550^{\circ} \mathrm{C}\right)$. Therefore, the concentration distribution of $\mathrm{OC}_{2}(120$ $250^{\circ} \mathrm{C}$ ) reflected well the distributions of organic acids. Furthermore, charring during sample-heating in the TOCA caused the laser adsorption of the sample to rise above the initial value. When the sample's laser adsorption returns to its initial value, an intersection with FID response gives the amount of pyrolytic organic carbon (Py-OC). Yu et al. (2002) have suggested that charring might be influenced by WSOC. In Saitama suburban samples, the correlation of Py-OC and WSOC was strong ( $r=0.96, n=12, p<0.001$; Fig. 4). Further, Py-OC in SPM had a strong correlation with $\mathrm{OA}(r=0.90)$, and also had good correlations with individual organic acids $\left(r=0.89\right.$ for $\mathrm{C}_{2}, 0.85$ for $\mathrm{C}_{3}, 0.93$ for $\mathrm{C}_{4}, 0.98$ for $\mathrm{WC}_{2}$ in Table $3 ; n=12, p<0.001$ ), indicating that these organic acids was closely related to the occurrence of OC charring.

\subsection{The Ratios of $\mathrm{C}_{3} / \mathrm{C}_{4}, \mathrm{C}_{6} / \mathrm{C}_{9}$, and $\mathrm{Ph} / \mathrm{C}_{9}$}

Table 5 shows the ratios of $\mathrm{C}_{3} / \mathrm{C}_{4}, \mathrm{C}_{6} / \mathrm{C}_{9}$, and $\mathrm{Ph} / \mathrm{C}_{9}$ in SPM, with literature data determined in different

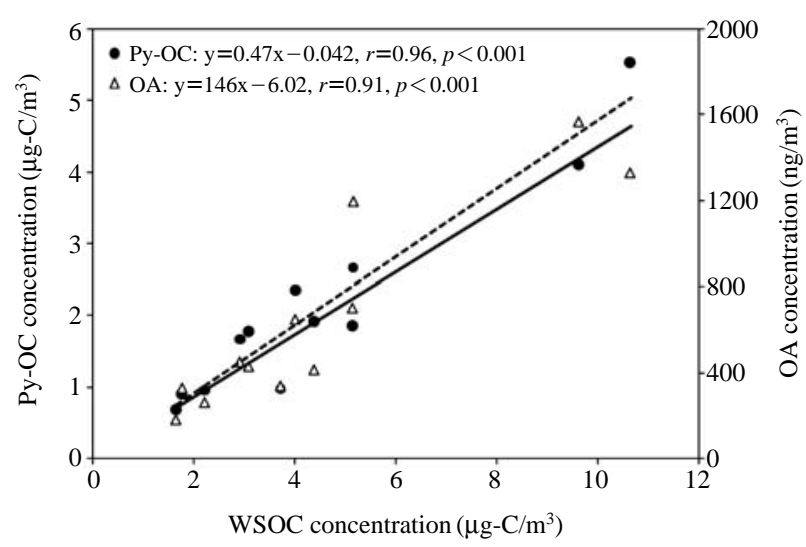

Fig. 4. Correlations of WSOC with Py-OC and OA in SPM in Saitama $(n=12)$.

environments (Hsieh et al., 2007; Ho et al., 2006; Kawamura and Yasuib, 2005; Ray and McDow, 2005; Graham et al., 2002; Wang et al., 2002; Kawamura and Sakaguchi, 1999).

$\mathrm{C}_{3}$ is derived from the incomplete combustion of fossil fuels or from secondary atmospheric production. Because $\mathrm{C}_{3}$ is thermally less stable than $\mathrm{C}_{4}$, the degradation of $\mathrm{C}_{3}$ in the combustion process is probably more significant than its production. The ratio of $\mathrm{C}_{3} / \mathrm{C}_{4}$ in particles can act as an informative indicator to distinguish secondary sources from primary vehicle exhaust in this regard: a $C_{3} / C_{4}$ ratio of $>3.0$ indicates photochemical production of dicarboxylic acids, whereas a ratio of 0.3-0.5 indicates a traffic-emissions origin of these dicarboxylic acids (Hsieh et al., 2007; Ho et al., 2006; Kawamura et al., 1996). As shown in Table 5, the $\mathrm{C}_{3} / \mathrm{C}_{4}$ ratio in Saitama suburban samples during summer was 1.61 and much higher than the level of pure traffic emissions, and also higher than ratios observed at urban sites (0.92 in Philadelphia, Ray and McDow, 2005; 1.00 in Tokyo, Kawamura and Yasuib, 2005; 1.44 in Hong Kong, Ho et al., 2006), indicating that $\mathrm{C}_{3}$ was in part produced secondarily by photochemical reactions in the atmosphere. However, the $C_{3} / C_{4}$ ratio in winter was very low $(0.66)$, reflecting the strong influence of vehicle exhaust.

Because $\mathrm{C}_{6}$ and $\mathrm{Ph}$ are produced by the atmospheric oxidation of anthropogenic sources, whereas $\mathrm{C}_{9}$ is produced from biogenic unsaturated fatty acids, $\mathrm{C}_{6} / \mathrm{C}_{9}$ and $\mathrm{Ph} / \mathrm{C}_{9}$ ratios may be used as a potential indicator of source strength of anthropogenic and biogenic precursors to organic acids in particles (Ho et al., 2006; Kawamura and Ikushima, 1993b). $\mathrm{C}_{6} / \mathrm{C}_{9}$ and $\mathrm{Ph} / \mathrm{C}_{9}$ ratios in summer in the present study $(0.50$ and 1.08$)$ were lower than ratios observed in Tokyo aerosols (1.49 and 2.36; Kawamura and Yasuib, 2005), suggesting that the relative contribution of biogenic to anthropogenic 
Table 5. Average concentrations $\left(\mathrm{ng} / \mathrm{m}^{3}\right)$ and their ratios of selected dicarboxylic acids reported in the literature.

\begin{tabular}{|c|c|c|c|c|c|c|c|c|c|c|c|c|c|}
\hline Site/type & Season & Size & Method & $\mathrm{C}_{2}$ & $\mathrm{C}_{3}$ & $\mathrm{C}_{4}$ & $\mathrm{C}_{6}$ & $\mathrm{C}_{9}$ & $\mathrm{Ph}$ & $\mathrm{C}_{3} / \mathrm{C}_{4}$ & $\mathrm{C}_{6} / \mathrm{C}_{9}$ & $\mathrm{Ph} / \mathrm{C}_{9}$ & Remark \\
\hline Philadelphia, USA/urban & Summer & $\mathrm{PM}_{10}$ & GC-MS & I & 14 & 15 & 2.0 & 1.0 & 4 & 0.92 & 2.00 & 3.50 & Ray and McDow, 2005 \\
\hline Nanjing, China/urban & Winter and spring & $\mathrm{PM}_{2.5}$ & GC-MS/FID & 660 & 89 & 113 & 37 & 144 & l & 0.78 & 0.25 & I & Wang et al., 2002 \\
\hline \multirow{2}{*}{ Hong Kong/urban road side } & Winter & $\mathrm{PM}_{2.5}$ & GC-MS/FID & 478 & 89 & 72 & 10.7 & 16.8 & 78 & 1.24 & 0.64 & 4.64 & Ho et al., 2006 \\
\hline & Summer & $\mathrm{PM}_{2.5}$ & GC-MS/FID & 268 & 48 & 33 & 12.7 & 9.1 & 90 & 1.44 & 1.40 & 9.92 & Ho et al., 2006 \\
\hline Tainnan, Taiwan/suburban & Autumn and summer & $\mathrm{PM}_{2.5}$ & IC & 449 & 21 & 30 & I & l & I & 0.70 & l & l & Hsieh et al., 2007 \\
\hline Robdinia, Brazil/pasture & Autumn & $\mathrm{PM}_{2.5}$ & GC-MS & 619 & 115 & 95 & 6.5 & 11.3 & 24 & 1.21 & 0.58 & 2.12 & Graham et al., 2002 \\
\hline Robdinia, Brazil/forest & Autumn & $\mathrm{PM}_{2.5}$ & GC-MS & 329 & 56 & 31 & 3.0 & 5.9 & 14 & 1.82 & 0.51 & 2.31 & Graham et al., 2002 \\
\hline Pacific Ocean/marine & Autumn and winter & TSP & GC-MS/FID & 40 & 11 & 2.8 & 2.1 & 0.57 & 0.66 & 3.93 & 3.68 & 1.16 & Kawamura and Sakaguchi, 1999 \\
\hline \multirow{2}{*}{ Tokyo, Japan/urban } & Summer & TSP & GC-MS/FID & 257 & 58 & 58 & 19.4 & 13.1 & 31 & 1.00 & 1.49 & 2.36 & Kawamura and Yasuib, 2005 \\
\hline & Winter & TSP & GC-MS/FID & 186 & 41 & 47 & 14.2 & 20.6 & 24 & 0.85 & 0.69 & 1.17 & Kawamura and Yasuib, 2005 \\
\hline \multirow{2}{*}{ Saitama, Japan/suburban } & Summer & SPM & GC-MS & 472 & 166 & 103 & 18.0 & 35.6 & 149 & 1.61 & 0.50 & 1.08 & This work \\
\hline & Winter & SPM & GC-MS & 94 & 15 & 23 & 7.9 & 23.9 & 56 & 0.66 & 0.33 & 2.33 & This work \\
\hline
\end{tabular}

inputs in summer in suburban Saitama was much more significant than those in Tokyo, a metropolitan adjacent to Saitama.

\section{CONCLUSIONS}

Saturated dicarboxylic acids, unsaturated dicarboxylic acids, ketocarboxylic acids, and dicarbonyls were determined in size-segregated samples with a high-volume Andersen air sampler at a suburban site in Saitama, Japan, during May 12-17 and July 24-27, 2007 and January 22-31, 2008. The seasonal average concentrations of these detected organic acids were $670 \mathrm{ng} / \mathrm{m}^{3}$, accounting for about $4.4-5.7 \%(\mathrm{C} / \mathrm{C})$ of WSOC and $2.3-3.6 \%(\mathrm{C} / \mathrm{C})$ of OC, respectively. Oxalic acid $\left(\mathrm{C}_{2}\right)$ was the most abundant species in the $\mathrm{SPM}$, followed by malonic $\left(\mathrm{C}_{3}\right)$, phthalic $(\mathrm{Ph})$ or succinic acid $\left(\mathrm{C}_{4}\right)$. Longer chain $n$-dicarboxylic acids were less abundant, except for azelaic acid $\left(\mathrm{C}_{9}\right)$. Glyoxylic acid $\left(\mathrm{WC}_{2}\right)$ and methyglyoxal (MeGly) were the most abundant ketocarboxylic acid and dicarbonyl, respectively, in the particles.

The $\mathrm{C}_{3} / \mathrm{C}_{4}$ ratio, which is an informative indicator to distinguish secondary sources from primary vehicle exhaust, was 1.41-1.61 during warm seasons and much higher than the level of pure traffic emissions, indicating that these dicarboxylic acids were in part produced secondarily by photochemical reactions in the atmosphere. Strong correlations were also observed between $\mathrm{C}_{2}, \mathrm{C}_{3}, \mathrm{C}_{4}$, and $\mathrm{WC}_{2}$. These organic acids also had strong correlations with oxidants and sulfate. These results are consistent with atmospheric oxidation processes that largely control the concentrations of these acids in suburban particles. The results of seasonal observations further indicated that photochemical reactions contributed more to the particulate organic acids in Saitama suburban areas than did direct emissions from anthropogenic and natural sources.
However, $\mathrm{Ph}$ and $\mathrm{C}_{6}$ concentrations were well correlated with EC in SPM, showing the intense effects of vehicle exhaust. Correspondingly, Ph showed smaller correlation coefficients with oxidants and sulfate than did other acids. These results suggested that $\mathrm{Ph}$ and $\mathrm{C}_{6}$ in SPM can be directly emitted from anthropogenic sources, especially from vehicles.

In spring and summer, the concentration of individual organic acid in fine particles $(<1.1 \mu \mathrm{m})$ exceeded half of the concentration in SPM. WSOC and most organic acids concentrations had similar size distributions as did sulfate, with a main peak in fine particles, indicating similar formation pathways. In winter, water-soluble organic acids in particles $(>1.1 \mu \mathrm{m})$ accounted for a larger proportion of the total in SPM. These results can be explained in terms of the lower winter temperatures, which strongly affected the gas/ particle repartitioning and oxidation pathways of semivolatile species, and further influenced the size distributions of water-soluble organic acids.

\section{ACKNOWLEDGEMENTS}

This work was supported in part by Grants-in-Aid from Saitama University.

\section{REFERENCES}

Abbatt J.P.D., K. Broekhuizen, and P. Pradeep Kumar (2005) Cloud condensation nucleus activity of internally mixed ammonium sulfate/organic acid aerosol particles. Atmospheric Environment, 39(26), 4767-4778.

Blando J.D. and B.J. Turpin (2000) Secondary organic aerosol formation in cloud and fog droplets: a literature evaluation of plausibility. Atmospheric Environment, 34(10), 1623-1632.

Chebbi A. and P. Carlier (1996) Carboxylic acids in the troposphere, occurrence, sources, and sinks: a review. 
Atmospheric Environment, 30(24), 4233-4249.

Chow J.C. and J.G. Watson (2002) PM $_{2.5}$ carbonate concentrations at regionally representative interagency monitoring of protected visual environment sites. Journal of Geophysical Research, 107(D21), 8344, doi: 10.1029/2001JD000574.

Cruz C.N. and S.N. Pandis (1998) The effect of organic coatings on the cloud condensation nuclei activation of inorganic atmospheric aerosol. Journal of Geophysical Research, 103(D11), 13111-13123.

Falkovich A.H., E.R. Graber, G. Schkolnik, Y. Rudich, W. Maenhaut, and P. Artaxo (2005) Low molecular weight organic acids in aerosol particles from Rondonia, Brazil, during the biomass-burning, transition and wet periods. Atmospheric Chemistry and Physics, 5, 781-797.

Graham B., O.L. Mayol-Bracero, P. Guyon, G.C. Roberts, S. Decesari, M.C. Facchini, P. Artaxo, W. Maenhaut, P. Köll, and M.O. Andreae (2002) Water-soluble organic compounds in biomass burning aerosols over Amazonia 1. Characterization by NMR and GC-MS. Journal of Geophysical Research, 107(D20), 1-15.

Hatakeyama S., M. Ohno, J. Weng, H. Takagi, and H. Akimoto (1987) Mechanism for the formation of gaseous and particulate products from ozone-cycloalkene reactions in air. Environmental Science and Technology, 21(1), 52-57.

Ho K.F., S.C. Lee, J.J. Cao, K. Kawamura, T. Watanabe, Y. Cheng, and J.C. Chow (2006) Dicarboxylic acids, ketocarboxylic acids and dicarbonyls in the urban roadside area of Hong Kong. Atmospheric Environment, 40(17), 3030-3040.

Hsieh L.Y., S.C. Kuo, C.L. Chen, and Y.I. Tsai (2007) Origin of low-molecular-weight dicarboxylic acids and their concentration and size distribution variation in suburban aerosol. Atmospheric Environment, 41(31), 6648-6661.

Jiang Z.W., Q.Y. Wang, K. Sekiguchi, and K. Sakamoto (2006) Investigation of variations in suspended particulate matter with enforcement of regulations on diesel vehicle exhaust in suburban Japan. JSME International Journal, 49(1), 2-7.

Jaffrezo J.L., G. Aymoz, C. Delaval, and J. Cozic (2005) Seasonal variations of the water soluble organic carbon mass fraction of aerosol in two valleys of the French Alps. Atmospheric Chemistry and Physics, 5, 39994036.

Kawamura K. (1993a) Identification of $\mathrm{C}_{2}-\mathrm{C}_{10} \omega$-Oxocarboxylic acids, pyruvic acid, and $\mathrm{C}_{2}-\mathrm{C}_{3} \alpha$-dicarbonyls in wet precipitation and aerosol samples by capillary GC and GC/MS. Anal. Chem., 65(23), 3505-3511.

Kawamura K. and K. Ikushima (1993b) Seasonal changes in the distribution of dicarboxylic acids in the urban atmosphere. Environmental Science and Technology, 27(10), 2227-2235.

Kawamura K., H. Kasukabe, and L.A. Barrie (1996) Source and reaction pathways of dicarboxylic acids, ketoacids and dicarbonyls in Arctic aerosols: one year of observations. Atmospheric Environment, 30, 17091722.

Kawamura K. and F. Sakaguchi (1999) Molecular distribution of water soluble dicarboxylic acids in marine aerosols over the Pacific Ocean including tropics. Journal of Geophysical Research, 104(D3), 3501-3509.

Kawamura K. and O. Yasuib (2005) Diurnal changes in the distribution of dicarboxylic acids, ketocarboxylic acids and dicarbonyls in the urban Tokyo atmosphere. Atmospheric Environment, 39(10), 1945-1960.

Kerminen V.-M., K. Teinilä, R. Hillamo, and T. Mäkelä (1999) Size-segregated chemistry of particulate dicarboxylic acids in the Arctic atmosphere. Atmospheric Environment, 33(13), 2089-2100.

Kerminen V.-M., C. Ojanen, T. Pakkanen, R. Hillamo, M. Aurela, and J. Meriläien (2000) Low-molecularweight dicarboxylic acids in an urban and rural atmosphere. Journal of Aerosol Science, 31(3), 349-362.

Limbeck A., H. Puxbaum, L. Otter, and M.C. Scholes (2001) Semivolatile behavior of dicarboxylic acids and other polar organic species at a rural background site (Nylsvley, RSA). Atmospheric Environment, 35(10), 1853-1862.

Li Y.C. and J.Z. Yu (2005) Simultaneous determination of mono and dicarboxylic acids, $\omega$-oxo-carboxylic acids, midchain ketocarboxylic acids and aldehydes in atmospheric aerosol samples. Environmental Science and Technology, 39(19), 7616-7624.

Narukawa M., K. Kawamura, N. Takeuchi, and T. Nakajima (1999) Distribution of dicarboxylic acids and carbon isotopic compositions in aerosols from 1997 Indonesian forest fires. Geophysical Research Letters, 26(20), 3101-3104.

Ortiz R., H. Hagino, K. Sekiguchi, Q.Y. Wang, and K. Sakamoto (2006) Ambient air measurements of six bifunctional carbonyls in a suburban area. Atmospheric Research, 82, 709-718.

Peng C., M.N. Chan, and C.K. Chan (2001) The hygroscopic properties of dicarboxylic and multifunctional acids: measurements and UNIFAC predictions. Environmental Science and Technology, 35(22), 4495-4501.

Ray J. and S.R. McDow (2005) Dicarboxylic acid concentration trends and sampling artifacts. Atmospheric Environment, 39(40), 7906-7919.

Röhrl A. and G. Lammel (2001) Low-molecular weight dicarboxylic acids and glyoxylic acid: seasonal and air mass characteristics. Environmental Science and Technology, 35(1), 95-101.

Saxena P. and L.M. Hildemann (1996) Water-soluble organics in atmospheric particles: A critical review of the literature and application of thermodynamics to identify candidate compounds. Journal of Atmospheric Chemistry, 24(1), 57-109.

Wang G., S. Niu, C. Liu, and L. Wang (2002) Identification of dicarboxylic acids and aldehydes of $\mathrm{PM}_{10}$ and $\mathrm{PM}_{2.5}$ aerosols in Nanjing, China. Atmospheric Environment, 36(12), 1941-1950.

Yao X.H., M. Fang, and C.K. Chan (2002) Size distribu- 
tions and formation of dicarboxylic acids in atmospheric particles. Atmospheric Environment, 36(13), 20992107.

Yu J.Z., J. Xu, and H. Yang (2002) Charring characteristics of atmospheric organic particulate matter in thermal analysis. Environmental Science and Technology, 36(4), 754-761.
Yu J.Z., X.-F. Huang, J. Xu, and M. Hu (2005) When aerosol sulfate goes up, so does oxalate: Implication for the formation mechanisms of oxalate. Environmental Science and Technology, 39(1), 128-133.

(Received 26 December 2008, accepted 10 April 2009) 